\title{
Effect of TB Therapy on the Health and Nutritional Status of Infants Aged 6 Months to 5 Years Diagnosed with Latent TB
}

\author{
Kasai Emmanuel Tebandite', Kampunzu Véronique Muyobela1, \\ Mukunda François Lusamaki², Bukaka Gaspard Mande' ${ }^{1}$, Gwendiza Jean Mopepe', \\ Sadiki Dady Falay ${ }^{1}$, Likele Bibi Batoko', Oloma Antoine Tshomba ${ }^{3}$, Dauly Nestor Ngbonda ${ }^{1}$, \\ Opara Jean Pierre Alworong'a ${ }^{1}$, Justin Ntokamunda Kadima ${ }^{4,5^{*}}$
}

\footnotetext{
${ }^{1}$ Department of Pediatrics, Faculty of Medicine and Pharmacy, University of Kisangani, Kisangani, Congo ${ }^{2}$ Department of Nutrition, Faculty of Medicine and Pharmacy, University of Kisangani, Kisangani, Congo ${ }^{3}$ Department of Public Health, Faculty of Medicine and Pharmacy, University of Kisangani, Kisangani, Congo ${ }^{4}$ Department of Pharmacy, Faculty of Medicine and Pharmacy, University of Kisangani, Kisangani, Congo ${ }^{5}$ Department of Pharmacy, Faculty of Medicine and Pharmacy, University of Rwanda, Kigali, Rwanda Email: *ntokamunda13@gmail.com, *kntokamunda@ur.ac.rw
}

How to cite this paper: Tebandite, K.E., Muyobela, K.V., Lusamaki, M.F., Mande, B.G., Mopepe, G.J., Falay, S.D., Batoko, L.B., Tshomba, O.A., Ngbonda, D.N., Alworong'a, O.J.P. and Kadima, J.N. (2018) Effect of TB Therapy on the Health and Nutritional Status of Infants Aged 6 Months to 5 Years Diagnosed with Latent TB. Journal of Tuberculosis Research, 6, 239-250. https://doi.org/10.4236/jtr.2018.64022

Received: September 13, 2018

Accepted: October 9, 2018

Published: October 12, 2018

Copyright @ 2018 by authors and Scientific Research Publishing Inc. This work is licensed under the Creative Commons Attribution International License (CC BY 4.0).

http://creativecommons.org/licenses/by/4.0/

\section{c) (i) Open Access}

\begin{abstract}
Background: Infants with latent tuberculosis are often subject to high morbidity, nutritional deficiency and mortality. Early treatment can prevent the onset of TB by reducing morbidity and improving nutritional status. This paper assessed whether preventive chemotherapy for $\mathrm{TB}$ can improve health and nutritional status of infants diagnosed with latent TB in Kisangani City. Method: Children diagnosed TB+ by tuberculin skin test and other clinical examinations were treated with Rifampicin, Isoniazid, Pyrazinamide and Ethambutol. Clinical symptoms and nutritional status were determined before to start treatment and at the $5^{\text {th }}$ month of treatment. Results: Out of 161 infants treated, $73(45.3 \%)$ were $<1$ year old, 49 (30.4\%) were 1 - 2 years old and $39(24.2 \%)$ were 3 - 5 years old. Both boys and girls were almost equally represented (50.3/49.7\%). The proportion of infants with fever $\left(\mathrm{T}>37^{\circ} \mathrm{C}\right)$ was $62.7 \%$ before treatment and $17.4 \%$ at the $5^{\text {th }}$ month of treatment; the difference was statistically significant $(p<0.001)$. Similarly, the proportion of children with weights below the ideal weight adjusted for each age decreased from $21.7 \%$ before treatment to $8.1 \%$ after treatment. Infants younger than one year were more likely to have fever than older children, while girls were more likely to be malnourished than boys $(\mathrm{p}<0.05)$ before treatment, but the recovery rates were not different. Conclusion: Treatment of infants diagnosed of latent TB prevents TB disease and improves nutritional status, but not in all cases. Control of fever and weight gain can be an indicator of good
\end{abstract}


outcome in poor health care settings.

\section{Keywords}

Tuberculosis, Infants, Treatment, Symptoms, Nutritional Status, Kisangani

\section{Introduction}

Childhood tuberculosis (CTB) is a very preoccupant public health problem all over the world, and more particularly in developing countries [1]. CTB accounts for about $15 \%$ to $40 \%$ of all tuberculosis (TB) cases. It is an important sentinel event suggesting a recent infection of infants through a contact with infectious adults in a community [1] [2] [3] [4] [5]. Early detection of CTB in children at high enough risk is useful for initiating preventive chemotherapy to avoid the active TB phase [6]. When screening is done, treatment is recommended for all children and adolescents diagnosed TB positive [7] [8] [9] [10]. This treatment requires strong adherence to prevent drug resistance and ensure good therapeutic results [11], but other factors such as age, gender, nutrition, and drug-related problems are susceptible to influence the treatment outcome [11] [12] [13]. For nutrition, there is evidence suggesting that malnutrition affects gene expression and immune function and predisposes children to progression of $\mathrm{TB}$; this results in active TB phase and inflammatory response that further worsen nutritional status [12] [13] [14] [15].

Thus, treatment of latent tuberculosis infection (LTBI) is the most effective strategy to prevent future cases of disease. Most cases of CTB in low-prevalence countries are preventable by screening for risk factors, testing for LTBI, and offering therapy [7] [8] [9] [10]. However, although LTBI therapy has been available and emphasized in rich nations, its use is limited in most resource-limited countries [16]. Various regimens have been used for a decade, but concerns about low completion rates, costs, and increasing rates of drug resistance have prompted research on shorter-course LTBI regimens and the use of combination regimens [17] [18]. The International Union against Tuberculosis and Lung Disease [17] completed a direct comparison of 3-, 6-, and 12-month regimens of INH in 27730 adults with tuberculin skin test (TST) induration $>6 \mathrm{~mm}$ and fibrotic pulmonary lesions seen on chest radiograph. During 5 years of follow-up, $1.4 \%$ of participants in the placebo group developed TB disease compared with $1.1 \%, 0.5 \%$, and $0.4 \%$ in the 3-, 6-, and 12 -month regimen groups, respectively. Among persons taking $\geq 80 \%$ of their INH doses, efficacy for the 12 -month regimen was higher ( $0.1 \%$ disease progression). Participants receiving the 6-month regimen had a 4-fold higher risk of $\mathrm{TB}$ disease than those receiving the 12-month regimen. Similar studies are rare in children. However, Hsu's observational studies [18] of 2494 children who were treated with INH daily for 1 year and followed on average for 6 years, showed greater than $99 \%$ protective efficacy 
given good adherence. It can be expected that the protective efficacy of INH should be substantially higher in young children because they have higher rates of disease progression without therapy.

A recent study in Kisangani [19] on a cohort of 593 children found a CTB prevalence of $40.3 \%$ using Tuberculin Skin Test, chest X-ray, laboratory and clinical investigations. All children diagnosed $\mathrm{TB}+$ received the first line anti-tuberculosis treatment. We designed this paper to describe the symptoms of the disease and the nutritional status of infants aged 6 months to 5 years and measure how preventive chemotherapy for TB can improve health and nutritional status in this group.

\section{Methods}

\subsection{Ethical Issue}

The study was conducted according to the guidelines laid down in the Declaration of Helsinki, and all procedures involving patients were approved by the Research Review Committee and Ethical Review Committee of the University of Kisangani $\mathrm{N}^{\circ} 05 / \mathrm{PED} / 2013$. Written informed consent was obtained from all legal guardians of the children.

\subsection{Study Design}

The complete protocol has been published elsewhere [19]. In summary (Figure 1), a cross-sectional study was conducted in 2013 to assess the prevalence of TB in children and adolescents 6 months to 17 years of age suspected of being infected with TB, using TST, chest X-ray, and clinical investigation.

Based on the analysis of patient medical records at the Pediatric Village Center of Kisangani University, of 593 children subjected to TST, 187 had a positive result $(\mathrm{TST}+)$ and were treated with anti-TB drugs. The 406 children who had a negative TST result were treated with common antibiotics, and of these, $52 \mathrm{did}$

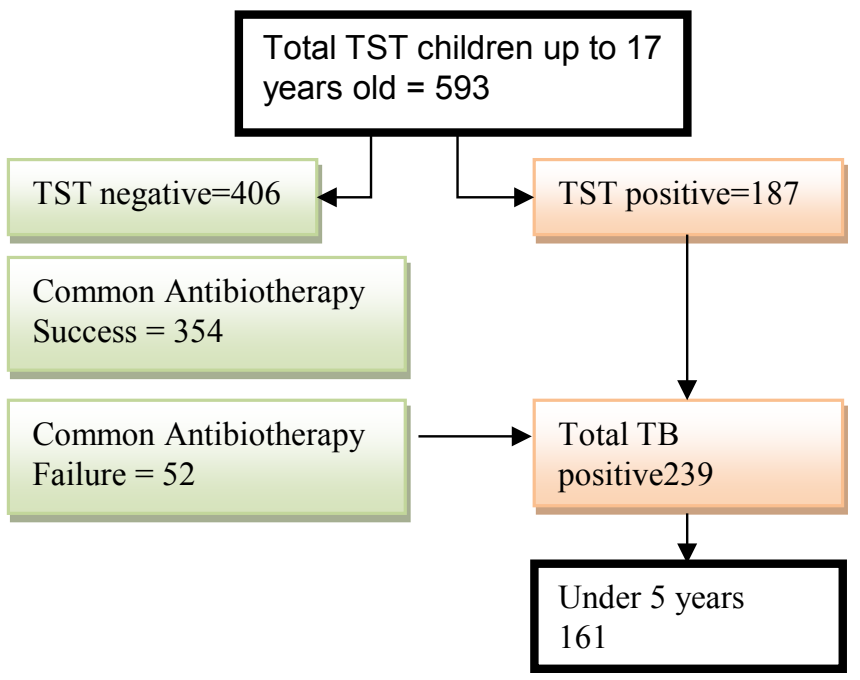

Figure 1. Flow chart of sampling. 
not respond to antibiotic therapy. All the 187 TST+ and 52 TST- clinically diagnosed as TB+ were subjected to TB therapy with 4 drugs. The four drugs, Rifampicin (R), Isoniazid (H), Pyrazinamide (Z), and Ethambutol (E) were administered as $2(\mathrm{RHZ})_{7}(\mathrm{E})_{7} / 7(\mathrm{RH})_{3}$ : first 2 months (intensive phase) and last 7 months (maintenance phase). To prevent polyneuritis as a treatment-related side effect, vitamin B6 therapy has been consistently associated with anti-TB drugs throughout the course of treatment. For this analysis, the 239 files of children treated for TB were retrieved and only 161 records of children less than 5 years of age, deemed appropriate to provide information on the clinical and nutritional response to treatment, were selected.

\subsection{Diagnostic Criteria}

Every child or adolescent aged 6 months to 17 years suspected of TB at the health center was eligible. TST was negative when the induration diameter (and not of the erythema) developed at the site of injection was $<5 \mathrm{~mm}$. In our case, given that Kisangani is a highly endemic area, there is a high probability of detecting both clinical silent and clinical active infection. A diameter $\geq 10$ was considered as active TB while between 5 and 10 was taken roughly as latent form. The criteria for suspicion were promiscuity (more or less than 4 persons sharing a room), contagion (history of living in contagious environment), BCG vaccination (presenting scar or not), chest images (consolidation/opacities, cavitations/cysts, linear opacities/fibrosis, nodules/masses, miliary pattern, lymphadenopathy, pleural abnormalities, trancheobronchial abnormalities, hilar adenopathy and leucocyte formula.

\subsection{Nutritional Status}

Anthropometry-Body weight and length, or height, are important indications of nutritional status of infants and young children. The nutritional status of children was appreciated by the degree of weight-loss and according to UNICEF-WHO classification which devises stunting by height-for-age index. The ideal weight for each age was estimated by the index (HAZ-score) which was calculated with ENA software for SMART 2011. A child below two standard deviations (-2 SD) from the median of the Child Growth Standards in terms of Weight-for-age was considered bad status [20].

\subsection{Variables}

Demographics: Age, sex, residence;

TB infection: TST Sensitivity (TB+/TST + and TB+/TST-);

Nutritional status: Symptoms: Weight loss;

Health status: Fever, coughs, physical exam, Sedimentation rate (SR): $>30$ $\mathrm{min} / \mathrm{h}$ or $<30 \mathrm{~min} / \mathrm{h}$, asthenia, anorexia, night swears.

\subsection{Data Analysis}

The data collected was analyzed with Excel Windows and SPSS v20 IBM soft- 
ware. We took underweight as weight $15 \%$ below the ideal-weight and fever when body temperature was $>37.5^{\circ} \mathrm{C}$. Pearson's chi-square was used to test the significance of differences at $\mathrm{p}<0.05$.

\section{Results}

\subsection{Demographic Variables}

Table 1 shows demographic variables. The majority came from Makiso health zone (58.39\%) followed by Tshopo (18.63\%), Kabondo (12.42\%), Mangobo (7.45\%), Kisangani $(2.48 \%)$ and Lubunga only $(0.62 \%)$. In the context of the study, boys and girls are almost equally represented $(50.31 \%$ vs. $49.69 \%)$. The majority of children 73 (45.34\%) were less than one year old, followed by $1-2$ years $49(30.43 \%)$ and $3-5$ years $39(24.22 \%)$.

\subsection{Clinical Diagnosis before Treatment}

Table 2 shows clinical investigations before TB chemotherapy. $72 \%$ of 161 infants were TST+ and $28 \%$ were TST-. About $26.7 \%$ were coughing and $64 \%$ had high sedimentation rate; the majority ( $>97 \%$ ) did not present asthenia, anorexia or night swears. The proportions did not vary significantly by sex or by age. In latent tuberculosis infection (LTBI), clinical warning signs are not well defined.

\subsection{Effect of Treatment on Health and Nutritional Status}

Table 3 shows the difference in body weight and body temperature before and after treatment. Before treatment, $62.7 \%$ had permanent fever $\left(\mathrm{T}>37.5^{\circ} \mathrm{C}\right)$, but after treatment, the score was reduced to $17.4 \%$ giving an improvement in $45.3 \%$ $(\mathrm{p}<0.001)$. The improvement was not influenced by gender $(\mathrm{p}=0.952)$ or age range $(\mathrm{p}=0.121)$. Similarly, regarding nutritional status, $21.7 \%$ were below the ideal weight, and after treatment, the score was reduced to $8.1 \%$ giving improvement of $13.6 \%(\mathrm{p}<0.001)$. All boys were upper the ideal weight before

Table 1. Demographic characteristics of patients disaggregated by residence, age and sex; $\mathrm{N}(\%)$.

\begin{tabular}{ccccccccccccc}
\hline & \multicolumn{3}{c}{ Gender } & \multicolumn{3}{c}{ Age } & \multicolumn{2}{c}{ Total } \\
\hline Health Zone & \multicolumn{2}{c}{ Male $^{*}$} & Female & $<1 y^{*}$ & $1-2$ y & $3-5$ y & \\
\hline & $N$ & $\%$ & $\mathrm{~N}$ & $\%$ & $\mathrm{~N}$ & $\%$ & $\mathrm{~N}$ & $\%$ & $\mathrm{~N}$ & $\%$ & $\mathrm{~N}$ & $\%$ \\
\hline Total & 81 & 50.31 & 80 & 49.69 & 73 & 45.34 & 49 & 30.43 & 39 & 24.22 & 161 & 100 \\
HZ1 Makiso* & 50 & 31.06 & 44 & 27.33 & 42 & 26.09 & 27 & 16.77 & 25 & 15.53 & 94 & 58.39 \\
HZ2 Tshopo & 12 & 7.45 & 18 & 11.18 & 15 & 9.32 & 8 & 4.97 & 7 & 4.35 & 30 & 18.63 \\
HZ3 Kabondo & 8 & 4.97 & 12 & 7.45 & 9 & 5.59 & 7 & 4.35 & 4 & 2.48 & 20 & 12.42 \\
HZ4 Lubunga & 3 & 1.86 & 1 & 0.62 & 2 & 1.24 & 1 & 0.62 & 1 & 0.62 & 4 & 2.48 \\
HZ5 Mangobo & 7 & 4.35 & 5 & 3.11 & 4 & 2.48 & 6 & 3.73 & 2 & 1.244 & 12 & 7.45 \\
HZ6 Kisangani & 1 & 0.62 & 0 & 0 & 1 & 0.62 & 0 & 0 & 0 & 0 & 1 & 0.62 \\
\hline
\end{tabular}

${ }^{*}$ Principal residence is Makiso; Majority age is $<1$ year $(\mathrm{p}<0.001)$; Majority sex is Male. 
Table 2. Frequency (\%) of Children presenting with indicated symptoms before treatment.

\begin{tabular}{ccccccc}
\hline Measurement & Total & \multicolumn{3}{c}{ Gender $(\mathrm{p}>0.05)$} & \multicolumn{3}{c}{ Age $(\mathrm{p}>0.05)$} \\
\hline TST+ & $\%$ & Male & Female & $<1$ Y & $1-2$ Y & $3-5 \mathrm{Y}$ \\
\hline Coughing & 72.0 & 74.0 & 70.0 & 74.0 & 71.4 & 69.2 \\
Sedimentation rate high & 26.7 & 25.9 & 27.5 & 28.8 & 20.4 & 30.8 \\
Asthenia & 64.0 & 67.9 & 60.0 & 58.9 & 75.5 & 59.0 \\
Anorexia & 1.2 & 2.5 & 0.0 & 1.4 & 2.0 & 0.0 \\
Night sweating & 2.5 & 2.5 & 2.5 & 2.7 & 2.0 & 2.6 \\
& 1.9 & 1.2 & 2.5 & 1.4 & 0.0 & 5.1
\end{tabular}

No significant difference $(\mathrm{p}>0.05)$.

Table 3. Body temperature and Body weight before and after Anti-TB treatment.

\begin{tabular}{|c|c|c|c|c|c|c|c|c|c|}
\hline \multirow[t]{2}{*}{ Measurement } & \multicolumn{2}{|l|}{ Total } & \multicolumn{3}{|c|}{ Gender } & \multicolumn{4}{|c|}{ Age (years) } \\
\hline & $\%$ & $\mathrm{p}-\mathrm{V}$ & $\%$ Male & $\%$ Female & $\mathrm{p}-\mathrm{V}$ & $\%<1$ & $\% 1-2$ & $\% 3-5$ & $\mathrm{p}-\mathrm{V}$ \\
\hline \multicolumn{10}{|l|}{ Fever } \\
\hline Before & 62.7 & & 63.0 & 62.5 & & 71.2 & 57.1 & 53.8 & \\
\hline After & 17.4 & & 18.5 & 16.3 & & 15.1 & 20.4 & 17.9 & \\
\hline (Before-After) & 45.3 & $<0.001^{\mathrm{ab}}$ & 44.5 & 46.2 & $0.952^{\mathrm{mf}}$ & 56.1 & 36.7 & 35.9 & $0.121^{\mathrm{ag}}$ \\
\hline \multicolumn{10}{|l|}{ Underweight } \\
\hline Before & 21.7 & & 0.0 & 43.8 & $<0.001^{\mathrm{mf}}$ & 47.9 & 0.0 & 0.0 & $<0.001^{\mathrm{ag}}$ \\
\hline After & 8.1 & & 4.9 & 11.3 & & 5.5 & 8.2 & 12.8 & \\
\hline (Before-After) & 13.6 & $<0.001^{\mathrm{ab}}$ & -4.9 & 32.5 & & 42.4 & -8.2 & -12.8 & \\
\hline
\end{tabular}

(ab): after-before; (mf): male-female; (ag): (age group).

treatment, but $4.9 \%$ became underweight at the $5^{\text {th }}$ month of treatment; $43.8 \%$ of girls were underweight before treatment, and $11.3 \%$ after treatment giving improvement in 32.5\%. The difference between boys and girls for weight is statistically significant $(\mathrm{p}<0.001)$. Concerning the age, before treatment $47.9 \%$ of infants $<1$ year were underweight while no one was underweight in the group $>1$ year. After treatment, only $5.5 \%$ of infants $<1$ year remained underweight giving improvement of $42.4 \%$. However, in the group $>1$ year, $8.2 \%-12.8 \%$ lost weight.

The general physical observation indicated that around $90 \%$ of infants were clinically in well health after treatment compared to the situation before treatment. Some patients presented complications and have been transferred to specialized health facilities.

\subsection{Limitation}

This study was not a highly randomized trial. Also the sample size is limited. However, the finding constitutes interesting starting point for an extended study 
over all the provinces of the country.

\section{Discussion}

The high prevalence of infants from Makiso health zone is due to the proximity of this zone with the healthcare facility that received children for screening and also because this $\mathrm{HZ}$ is the municipality that offers a lot of commercial activities compared to others; this may drain a lot of people including bacilliferous coughers as source of infection for children.

The distribution of the sample by gender and age showed that the risk of developing TB in infants is the same for both boys and girls even though slightly biased to males $(\mathrm{OR}=1.01)$. Generally, infectious diseases rarely affect males and females equally and tuberculosis is no exception [21]. Globally in adult persons, far more men than women are significantly at risk of contracting and dying from TB. According to the WHO report 2013, the degree of male bias varies by geographic location and by year [22]. Considering the overall trends in the 20 high-burden countries for which data are available, the median male-to-female ratio is 1.8:1, with only Afghanistan reporting a ratio of $<1: 1$. The consistent global trend for male bias in tuberculosis has been attributed to environment factors as well as to biological or physiological differences [22] [23] [24]. Smoking, alcohol drinking, travelling and place of work expose men to TB while hormonal system may protect women. In children under-5, those risk factors are less likely to apply.

The incidence of $\mathrm{TB}$ in this study decreased inversely with age, $45.3 \%$ in children $<1$ year of age, $30.4 \%$ in 1 - 2 years old and $24.2 \%$ in 3 - 5 years old; this is consistent with the concept of age pyramid. Many studies have found that the lower is the age, the higher is the risk for a child exposed to have a TB infection [1] [3] [19]. The predominance of children under one year of age confirms the vulnerability of this period of childhood development in relation with the immaturity of cellular immunity [25]. It has been reported that among children under 1 year of age, approximately 30\% - 40\% may progress from primary infection to active disease; for children aged between 1 and 5 years old, this risk is approximately 24\%; the risk of progression declines slowly beyond 5 years and increases again at around 10 years of age [25] [26] [27]. The risk factors for progression from primary infection to disease include duration and burden of exposure, the virulence of the mycobacterial strain, HIV infection or other clinical conditions that impair the immune system, malnutrition, and exposure to tobacco smoke [28].

The general functional signs found in adults TB patients are fever $\left(38^{\circ} \mathrm{C}\right)$, profuse nocturnal sweating, anorexia, asthenia, chronic cough with sputum, chest pain and/or dyspnea [1] [2]. Among the functional or physical signs found in this study, more than $98 \%$ had no asthenia, anorexia, perspiration; only the prevalence of fever, loss of weight and elevation of sedimentation rate were significantly indicative signs of the disease. It is known that the diagnosis of TB in 
children is difficult because it presents poor and almost atypical symptomatology and also because of its paucibacillary character [19]. In latent tuberculosis infection (LTBI), the presence of TB disease symptoms is almost absent and the mycobacterium may also be absent in well-contained media such as cervical adenitis. In this case only the TST or calcified lymph node on chest radiograph (CXR) may be the only evidence of prior TB infection [29] [30] [31]. In clinical practice, the diagnosis requires a systematic approach that comprises 3 fundamental steps: 1) clinical history and detailed physical examination; 2) imaging evaluation and 3) identification of the pathogen [32]. New diagnostic methods are promising such interferon-gamma assay [32] [33].

For the treatment, there are 2 main options for chemotherapy: 9 or 6 month regimen [34] [35] [36] [37]. The 9-month regimen is preferred because it is more effective. The Centers for Disease Control and Prevention (CDC) has issued updated recommendations regarding the use of 3HP (once-weekly isoniazid-rifapentine for 12 weeks). The CDC expanded its recommendation for the $3 \mathrm{HP}$ regimen for the treatment of LTBI to include patients aged 2 to 11 years old; patients with comorbid HIV infection (including AIDS) who are taking antiretrovirals with acceptable drug-drug interactions with rifapentine, and as either DOT or self-administered therapy (SAT) in those $\geq 2$ years old. WHO recommends the following dosages of antituberculosis drugs for the treatment of tuberculosis in children [38]: isoniazid (H) $-10 \mathrm{mg} / \mathrm{kg}$ (range $10-15 \mathrm{mg} / \mathrm{kg}$ ); maximum dose $300 \mathrm{mg} /$ day; rifampicin (R) $-15 \mathrm{mg} / \mathrm{kg}$ (range $10-20 \mathrm{mg} / \mathrm{kg}$ ); maximum dose $600 \mathrm{mg} /$ day; pyrazinamide (Z) $-35 \mathrm{mg} / \mathrm{kg}(30-40 \mathrm{mg} / \mathrm{kg}$ ); ethambutol (E) $-20 \mathrm{mg} / \mathrm{kg}(15-25 \mathrm{mg} / \mathrm{kg})$. The selection of a 3-drug or 4-drug regimen is based on the location of tuberculosis, risk of isoniazid resistance and prevalence of HIV [39]. To treat TB+ children in this study, the standard treatment regimen (first-line anti-tuberculosis drugs) which included rifampicin, isoniazid, pyrazinamide and ethambutol for the first 2 months and only rifampicin and isoniazid at the continuation phase was applied. This scheme is recommended when resistance to the usual isoniazid is suspected [40]. We have used this scheme as at priory we could not discriminate sensitive and resistant cases. We also systematically added Vitamin B6 to prevent isoniazid peripheral neuropathy side effect that occurs especially in malnourished children and in slow acetylors [40] [41] [42].

Globally, the clinical treatment outcome was good in more than $90 \%$ of cases. This result demonstrates that the success of chemotherapy for antitubercular prophylaxis is maximal in children [12]. This success is explained by a good adherence to treatment, which is due to the rarity of side effects in children [40]. The intervention reduced the prevalence of fever as well as that of underweight. The proportions of children with temperature $>37^{\circ} \mathrm{C}$ decreased from $62.7 \%$ before to $17.4 \%$ after treatment. The underweight varied almost in the same order from $21.7 \%$ to $8.1 \%$. The good outcome was noted in both TST+ and TST-children. The good response noted in children TST negative demonstrates 
that some children with TB have not been diagnosed with TST probably because of their state of skin anergy. This is common in cases of malnutrition or HIV infection and may be due to immunodeficiency ${ }^{12}$. However, $100 \%$ of males were upper ideal weight before treatment but $4.9 \%$ went underweight during treatment; $47.9 \%$ of children $<1$ year were underweight while no one was underweight among older before treatment. Finally, 4.9 to $12.8 \%$ could have lost weight during treatment; the reason was not defined, but perhaps they were not responding to the treatment [43].

\section{Conclusion}

There is a significant statistical difference between pre-treatment and posttreatment values. Girls under one year of age are at higher risk of fever and malnutrition during the pre-phase of active tuberculosis. The study highlights that TST remains the most useful tool for quickly diagnosing TB in children. Children under 5 years of age are most at risk of developing active TB in an endemic environment. The first-line anti-tuberculosis drugs still work for the management of childhood tuberculosis. Since the metabolic rate of isoniazid may be slow leading to peripheral polynevritis, vitamin B6 may be combined to the treatment regimen.

\section{Conflicts of Interest}

The authors declare no conflict of interest.

\section{References}

[1] World Health Organization (2017) Global Tuberculosis Report. Geneva.

[2] American Academy of Pediatrics, Committee on Infectious Diseases (2015) 2015 Red Book: Report of the Committee on Infectious Diseases. 30th Edition, AAP, Elk Grove Village, IL.

[3] Luzzati, R., Migliori, G.B., Zignol, M., Cirillo, D.M., Maschio, M., Tominz, R., et al. (2017) Children under 5 Years Are at Risk for Tuberculosis after an Occasional Contact with Highly Contagious Patients: An Outpatient Outbreak from a Smear Positive Health Care Worker. European Respiratory Journal, 50, Article ID: 1701414. https://doi.org/10.1183/13993003.01414-2017

[4] Lienhardt, C., Sillah, J., Fielding, K., Donkor, S., Manneh, K., Warndorff, D., et al. (2003) Risk Factors for Tuberculosis Infection in Children in Contact with Infectious Tuberculosis Cases in the Gambia, West Africa. Pediatrics, 15, e608-e614. https://doi.org/10.1542/peds.111.5.e608

[5] Khalilzadeh, S., Baghaie, N., Boloorsaz, M.R., Hakimi, M., Amari, S. and Ali Velayati, A.A. (2003) Screening of Tuberculosis in Symptomatic Close Contact Children. Tanoffos, 2, 51-56.

[6] Roya-Pabon, C.L. and Perez-Velez, C.M. (2016) Tuberculosis Exposure, Infection and Disease in Children: A Systematic Diagnostic Approach. Pneumonia, 8, 23. https://doi.org/10.1186/s41479-016-0023-9

[7] WHO (2015) WHO Guidelines on the Management of Latent Tuberculosis Infection. Geneva. http://www.who.int/tb/publications/ltbi_document_page/en/ 
[8] Tsai, K.S., Chang, H.L., Chien, S.T., Chen, K.L., Chen, K.H., Mai, M.H. and Chen, K.T. (2013) Childhood Tuberculosis: Epidemiology, Diagnosis, Treatment, and Vaccination. Pediatrics \& Neonatology, 54, 295-302. https://doi.org/10.1016/j.pedneo.2013.01.019

[9] Mandal, N., Anand, P.K., Gautam, S., Das, S. and Hussain, T. (2017) Diagnosis and Treatment of Pediatric Tuberculosis: An Insight Review. Critical Reviews in Microbiology, 43, 466-480. https://doi.org/10.1080/1040841X.2016.1262813

[10] Zar, H.J., Eley, B., Nicol, M.P., Figaji, A. and Hawkridge, A. (2012) Advances in Childhood Tuberculosis-Contributions from the University of Cape Town. South African Medical Journal, 102, 518-521. https://doi.org/10.7196/SAMJ.5552

[11] Centers for Disease Control and Prevention (2014) Managing Tuberculosis Patients and Improving Adherence. CDC, Atlanta, GA.

[12] Chisti, M.J., Ahmed, T., Shahid, A.S., Shahunja, K.M., Bardhan, P.K., Faruque, A.S., et al. (2015) Sociodemographic, Epidemiological, and Clinical Risk Factors for Childhood Pulmonary Tuberculosis in Severely Malnourished Children Presenting with Pneumonia: Observation in an Urban Hospital in Bangladesh. Global Pediatric Health, 2, Article ID: 2333794X15594183.

[13] Jaganath, D. and Ezekiel, M. (2012) Childhood Tuberculosis and Malnutrition. The Journal of Infectious Diseases, 206, 1809-1815. https://doi.org/10.1093/infdis/jis608

[14] Sathenahalli, V.B., Minarey, N., Gornale, V., Kumar, R., Joshi, K. and Singh, H.P. (2015) Association of Tuberculosis with Severe Acute Malnutrition. Journal of Evolution of Medical and Dental Sciences, 4, 11865-11870. https://doi.org/10.14260/jemds/2015/1710

[15] Tendai, M., Chabala, C., Chama, E., Mugode, R., Kapata, N., Musonda, P. and Michelo, C. (2017) Tuberculosis Caseload in Children with Severe Acute Malnutrition Related with High Hospital Based Mortality in Lusaka, Zambia. BMC Research Notes, 10, 206.

[16] Cruz, A.T., Ahmed, A., Mandalakas, A.M. and Starke, J.R. (2013) Treatment of Latent Tuberculosis Infection in Children. Journal of the Pediatric Infectious Diseases Society, 2, 248-258. https://doi.org/10.1093/jpids/pit030

[17] International Union against Tuberculosis Committee on Prophylaxis (1982) Efficacy of Various Durations of Isoniazid Preventive Thearpy for Tuberculosis: Five Years of Follow-Up in the IUAT Trial. Bull World Health Organ, 60, 555-564.

[18] Hsu, K.H. (1974) Isoniazid in the Prevention and Treatment of Tuberculosis: A 20-Year Study of the Effectiveness in Children, JAMA, 229, 528-533. https://doi.org/10.1001/jama.1974.03230430020019

[19] Tebandite, K.E., Ngbonda, D.N., Alworonga, O.J.P., Batoko, L.B. and Kadima, N.J. (2017) Spectrum of Childhood Tuberculosis: Ensuring and Making a Differential Diagnosis by Tuberculin Skin Test and Clinical Signs in Kisangani, DR Congo. IJTDH, 23, 1-10.

[20] Lusamaki, M.F., Tebandite, E.K., Alworonga, O.J.P., Batina, A.S., Kayisu, K.A. and Kadima, N.J. (2017) Effectiveness of UNICEF Multiple Micronutrient Powder on Child Stunting Rate and Influencing Factors in Kisangani. European Journal of $\mathrm{Nu}$ trition \& Food Safety, 7, 179-188. https://doi.org/10.9734/EJNFS/2017/36276

[21] Guerra, S.F. and Abad, F.F. (2013) Sex bias in Infectious Disease Epidemiology: Patterns and Processes. PLOS ONE, 8, e62390. https://doi.org/10.1371/journal.pone.0062390

[22] WHO (2010). http://www.who.int/tb/areas-of-work/population-groups/gender/en/ 
[23] Nhamoyebonde, S. and Leslie, A. (2014) Biological Differences between the Sexes and Susceptibility to Tuberculosis. The Journal of Infectious Diseases, 209, S100-S106.

[24] Hamid, S.M.A., Declercq, E., Van Deun, A. and Saki, K.A. (2004) Gender Differences in Tuberculosis: A Prevalence Survey Done in Bangladesh. International Journal of Tuberculosis and Lung Disease, 8, 952-957.

[25] Driessche, K.V., Persson, A., Marais, B.J., Fink, P.J. and Urdahl, K.B. (2013) Immune Vulnerability of Infants to Tuberculosis. Clinical \& Developmental Immunology, 2013, Article ID: 781320.

[26] Lamb, G.S. and Starke, J.R. (2017) Tuberculosis in Infants and Children. Microbiology Spectrum, 5. https://doi.org/10.1128/microbiolspec.TNMI7-0037-2016

[27] Carvalhoa, I., Goletti, D., Mangac, S., Silva, D.R., Manissero, D. and Migliorif, G. (2018) Managing Latent Tuberculosis Infection and Tuberculosis in Children. Pulmonology, 24,106-114.

[28] Lienhardt, C., Fielding, K., Sillah, J.S., et al. (2005) Investigation of the Risk Factors for Tuberculosis: A Case-Control Study in Three Countries in West Africa. International Journal of Epidemiology, 34, 914-923. https://doi.org/10.1093/ije/dyi100

[29] Shingadia, D. and Novelli, V. (2003) Diagnosis and Treatment of Tuberculosis in children. The Lancet Infectious Diseases, 3, 624-632.

https://doi.org/10.1016/S1473-3099(03)00771-0

[30] Moore, D.P., Schaaf, H.S., Nuttall, J. and Marais, B.J. (2009) Childhood Tuberculosis Guidelines of the Southern African Society for Paediatric Infectious Diseases. Southern African Journal of Epidemiology and Infection, 24, 57-68. https://doi.org/10.1080/10158782.2009.11441353

[31] Moyo, N., Tay, E.L. and Denholm, J.T. (2015) Evaluation of Tuberculin Skin Testing in Tuberculosis Contacts in Victoria, Australia, 2005-2013. Public Health Action (PHA), 5, Article ID: 188193. https://doi.org/10.5588/pha.15.0018

[32] Chisti, M.J., Salam, M.A., Raqib, R., Banu, S., Shahid, A.S., Shahunja, K.M., et al. (2015) Validity of Antibodies in Lymphocyte Supernatant in Diagnosing Tuberculosis in Severely Malnourished Children Presenting with Pneumonia. PLoS ONE, 10, e0126863. https://doi.org/10.1371/journal.pone.0126863

[33] Thomas, B., Pugalenthi, A., Patel, H., Woltmann, G., Bankart, J. and Hoskyns, W. (2011) Concordance between Tuberculin Skin Test and Interferon-Gamma Assay and Interferon-Gamma Response to Mitogen in Pediatric Tuberculosis Contacts. Pediatric Pulmonology, 46, 1225-1232.

[34] World Health Organization (2006) Anti-Tuberculosis Treatment in Children. Geneva, Switzerland. International Journal of Tuberculosis and Lung Disease, 10, 1205-1211. https://doi.org/10.1002/ppul.21494

[35] Wubshet, O.Z., Demissie, M., Agedew, E. and Misker, D. (2017) Rifampicin-Versus Ethambutol-Based Continuation Phase Anti Tuberculosis Treatment Regimen Is among Factors Associated with Treatment Outcomes in Patients Treated at Six Health Facilities in Southern Ethiopia. Quality in Primary Care, 25, 1-6.

[36] Frydenberg, A.R. and Graham, S.M. (2009) Toxicity of First-Line Drugs for Treatment of Tuberculosis in Children: Review. Tropical Medicine and International Health, 14, 1329-1337. https://doi.org/10.1111/j.1365-3156.2009.02375.x

[37] Berti, E., Galli, L., Venturini, E., de Martini. M. and Chiappini, E. (2014) Tuberculosis in Childhood: A Systematic Review of National and International Guidelines. BMC Infectious Diseases, 14, S3. https://doi.org/10.1186/1471-2334-14-S1-S3 
[38] WHO (2014) Guidance for National Tuberculosis Programmes on the Management of Tuberculosis in Children. 2nd Edition, WHO, Geneva, Switzerland.

[39] Santos, G., Oliveira, O., Gaio, R. and Duarte, R. (2017) Effect of Isoniazid Resistance on the Tuberculosis Treatment Outcome. Archivos de Bronconeumología, 54, 48-51.

[40] Mukanyangezi, M.F., Kadima, N.J. and Musemakweri, A. (2015) Determination of Isoniazid Acetylator Phenotype and Its Clinical Implication in Rwandan TB-Patients. Rwanda Journal Series F: Medicine and Health Sciences, 2, 6-12.

[41] Bass, J.B., Farer, L.S., Hopewell, P.C., O’Brien, R., Jacobs, R.F., Ruben, F., Snider, D.E. and Thornton, G. (1994) Treatment of Tuberculosis and Tuberculosis Infection in Adults and Children. American Thoracic Society and the Centers for Disease Control and Prevention, 149, 1359-1374.

[42] Yang, H., Enimil, A., Gillani, F.S., Antwi, S., Dompreh, A., Ortsin, A., et al. (2017) Evaluation of the Adequacy of the 2010 Revised World Health Organization recommended Dosages of the First Line Antituberculosis Drugs for Children. The Pediatric Infectious Disease Journal, 37, 43-51.

[43] Khan, A., Sterling, T.R., Reves, R., Vernon, A. and Horsburgh, C.R. (2006) Lack of Weight Gain and Relapse Risk in a Large Tuberculosis Treatment Trial. American Journal of Respiratory and Critical Care Medicine, 174, 344-348.

https://doi.org/10.1164/rccm.200511-1834OC 